\title{
“Aren't we all a little bisexual?” The Recognition of Bisexuality in an Unlikely Place
}

The hypermasculine subculture of men’s teamsports has traditionally been characterized by the one-time rule of homosexuality, where one same-sex sexual experience is normally equated with a homosexual orientation. Thus, men have been polarized into sexual identity categories, erasing bisexuality as a legitimate or viable category of sexual identification. However, in this research we examine the perspectives on bisexuality among 60 male soccer players from three strategically selected U.S. universities, showing that these athletes accept bisexuality as a legitimate and non-stigmatized sexual identity. We find that they intellectualize an understanding of bisexuality in highly complex ways. We also highlight that while only a very small minority have engaged in same-sex sexual behaviors, at some level, most players recognize some degree of bisexuality in their own identities. We suggest that these results are a product of increased exposure to and contact with homosexual persons, leading to decreasing cultural homohysteria, finally resulting in increasingly open discussion and complex understanding of sexual behaviors and identities that were once erased or stigmatized in men's teamsport culture.

Keywords: bisexuality, heteromasculinity, homophobia, homosexuality, sport, 


\section{Sport and the One-Time Rule of Homosexuality}

From early youth, and throughout young adulthood, boys and men are encouraged to participate in teamsports (c.f. Latinen \& Tiihonen, 1990; Mills, 1997; O’Donnell, Walters, \& Wardlow, 1998). Here, they are structured into a desire to be associated with hegemonic sexual and gender dominance by partaking in a sporting culture that uses violence and homophobia to sculpt bodies and shape identities to align with the culturally dominant heteromasculine form (Anderson, 2005). In other words, teamsport participation is understood to provide boys with opportunities to establish and display a heterosexual form of hypermasculinity (Pascoe, 2003; Ricciardelli, McCabe, \& Ridge, 2006). Competitive teamsports (such as soccer) therefore exist as a microcosm of society's sexual and gendered values, myths and prejudices about the variations in men and women, while also actively constructing men to exhibit, value and reproduce traditional notions of heteromasculinity (Britton \& Williams, 1995; Burstyn, 1999; Burton-Nelson, 1994; Messner, 1992).

The literature concerning men's teamsports shows that this conservative culture has also limited athletes' awareness of the fluidity of sexuality. Among teamsport athletes, one same-sex sexual experience is traditionally equated with a homosexual orientation (Pronger, 1990; Messner, 2004). However, if just one samesex behavior is associated with a homosexual identity, then men are culturally equated into one of only two viable categories of sexuality: homosexuality or heterosexuality (Anderson, 2008). This cultural conflation (of any same-sex behavior as being consistent with the sexual identity of homosexuality) effectively erases bisexuality as a viable category of sexual identification.

Borrowing from the one-drop theory of race (Davis, 1991; Harris, 1964), in which a dominant White culture once viewed anyone with even a portion of Black 
genetic ancestry as Black, Anderson (2008) applies this theory to sexuality, calling the behavioral component of this model the one-time rule of homosexuality. This is because one same-sex sexual experience is normally equated with a homosexual orientation, ruling out the possibility of men engaging in recreational same-sex sex without being homosexualized by their behavior.

However, the inverse of this rule does not apply evenly to straight men. Schwartz (1995, p. 12) therefore says, "We have to rethink how we have demonized the power of homosexuality so that we assume it to be the greater truth of our sexual self_-as if one drop of homosexuality tells the truth of self while one drop of heterosexuality in a homosexual life means nothing.” This one-way application of the one-time rule also creates a double jeopardy for men who reveal that they have experience with same-sex sex as it both disqualifies them from achieving the requisites of heterosexuality and it diminishes their masculine capital among peers (Anderson, 2005a). While Reis (1961) and Alan Klein (1993) show some heterosexual men (e.g. those who financially profit from sex with men) are less inclined to fear gay stigma, and same-sex sex is also less threatening to heterosexual men in certain homogenous, masculine institutions, like prisons and the military (Bérubé, 1991; Gear \& Ngubeni, 2002), the general rule seems to be that for most heterosexual men in contemporary North American culture, their socially perceived heterosexual identities are partially conditioned upon exclusively opposite-sex sexual behaviors (Butler, 1990).

While this tendency to polarize sexual identities limits our sexual/emotional range as human beings, it serves a functional/conservative purpose. By polarizing sexual identities to straight or gay, Klein (1993) suggests that men are provided with a method of eliminating the threats of uncertainty and fear that the recognition of their 
own bisexuality triggers inside them. However, the one-time rule does more than just limit sexual behaviors and expression of bisexuality.

Multiple gender scholars have also shown that, in periods of high homophobia, emotional and physical intimacy between men is discouraged because it too is associated with a homosexual identity (c.f. Ibson, 2002). Accordingly (and contrasting physical affection between women), when homosocial tactility or emotional intimacy occurs between men, it is almost always mis/taken for sexual desire (Thompson, 2006). Klein (1993) suggests that men’s avoidance of emotional and physical intimacy is perpetuated by a myth that such intimacies are inspired by sexual desire and are precursors to sexual intimacy. Indeed, sexual desire is often perceived as the traditional missing link between a friendship and a romantic relationship (Thompson, 2006). Thus, to ensure the separation of sexual desire from their lives, men also avoid homosocial emotional and physical intimacy. This has traditionally left boys and men prohibited from holding hands, softly hugging, caressing, or kissing, in either public or private (Kaplan, 2006). Men’s demonstrations of intimacy are, therefore, generally relegated to the hyper-masculinized spheres, such as playing sports.

Anderson (2009) theorizes that all of this derives from a culture of extreme homohysteria—something that he defines as heterosexual men’s fear of being publicly homosexualized if they violate rigid boundaries of heteromasculinity. Thus, it is not just homophobia (a dislike of homosexuals) that drives this limiting culture; it is the fear of being socially perceived as feeling same-sex sexual desires. Accordingly, the contextual level of cultural homohysteria is affected by the expression of men's cultural homophobia. Because teamsports have previously been described as bastions of homophobia (Pronger, 1990), men in teamsports have used participation to try and distance themselves from being thought gay (Anderson, 2005). 
Thus, a culture of homohysteria compels men to join hyper-heterosexualized organizations (such as sport). This means that sport has been particularly resilient in reproducing a conservative form of orthodox sexuality as homophobia/biphobia has been used to maintain this culture.

\section{Bye Bi Myths of Bisexuality}

Bisexuality has, of course, faced more challenges than just its erasure among teamsport athletes. In recent times, stigmatization and discrimination have been documented as characteristic of the bisexual individuals' life experience (Barrios, Corbitt, Estes \& Topping, 1976; Herek, 2002; Mohr, Israel \& Sedlacek, 2001). In less polarizing subcultures, those identifying as bisexual have often been stigmatized as neurotic, unable to love, or “incapable of making up their minds.” Bisexual individuals have also been subject to double discrimination, facing hostility from both heterosexuals and homosexuals (Ochs, 1996).

Furthermore, bisexuals have sometimes been described as simply being in transition into pure homosexuality, or being sex crazed (Klein, F. 1993). Thus, the overwhelming social attitude toward bisexuality has been one of denial, erasure, and/or stigma. This is even evident in academic literature, which favors selfidentification over one's sexual predisposition (c.f. Eigenberg, 2000). In other words, men 'who have sex with men' are regarded as being “on the down-low,” curious, or heteroflexible, rather than simply bisexual (c.f. Denizet-Lewis, 2003; King, 2004).

These myths and misattributions may however be relegated to a particularly conservative period of American history. Youths’ attitudes toward sex and sexuality are changing — and they are changing rapidly. Recent decades have brought an erosion of orthodox views and institutional control of sexual behaviors and relationships in 
North American and Western European cultures (Joyner \& Laumann, 2001). This is made evident in the growing percentage of people who engage in pre-marital intercourse (Laumann, Gagnon, Michael, \& Michaels, 1994; Johnson et al., 2001), the social and legal acceptance of divorce (Jackson \& Scott, 2003), the markedly expanded social and political landscape for gays and lesbians (Anderson, 2009; Loftus, 2001), and what some would suggest is a lessening of the traditional double standard for heterosexual intercourse, permitting women to have casual sex with less social stigma (Tanenbaum, 1999; Wolf, 1997).

For university students, there also exists a culture where many students avoid romantic relationships. Instead, undergraduates frequently engage in casual sex, something they call hooking up (Boogle, 2008; Stepp, 2007). These trends have been suggested to increase the viability of alternative categories of sexuality, expand social and political landscapes for sexual minorities, and to reduce the disparity between acceptable gendered behaviors or at least create more space for the open discussion of behaviors traditionally coded as non-heteromasculine (c.f. Anderson, 2005, 2008; Barnett \& Thomson, 1996; Loftus, 2001; Tanenbaum, 1999; Wolf, 1997).

More specific to the current paper, despite decades of overt homophobia in teamsports, there is evidence to suggest things are changing. More progressive attitudes about sexuality are becoming esteemed among young men in western cultures (Anderson, 2002, 2005, 2009; Harris \& Clayton, 2007; Price \& Parker, 2003; Pringle \& Markula, 2005; Southall, Nagel, Anderson, Polite, \& Southall, 2009). Further, as reductions in cultural homophobia/homohysteria occur, a cultural space is opened for the recognition of sexualities and/or sexual behaviors that have been previously silenced and stigmatized. 
For example, Anderson’s (2009, 2008a, b, c) studies of heterosexual male athletes find them to display positive attitudes toward homosexuality, to value homosocial emotional intimacy, as well as homosocial physical tactility. Supporting these findings, Schrack-Walters, O’Donnell, and Wardlow’s (2009) qualitative analysis of men's participation in athletics suggests that the development of communal and emotional affects is becoming increasingly more important between men on sports teams and finds that comments from athletes were laden with emotional intimacy. And, encouragingly, when they heard men "express very high levels of affection for each other, none of the athletes qualified their statements using a heterosexual standard of acceptability” (Schrack-Walters et al., 2009, p.92). Importantly, their data suggests that representing male athletes as monolithic 'jock' individuals is an unfair representation of the experiences and gendered identities of all male athletes. Given the strong culture of hyper-masculinity in teamsports, as previously stated, it is not, however, completely clear what developmental, interpersonal and social contexts influenced the deviations from traditional male gender role discourses found in their results. The current paper takes this research further by exploring the sexual and gendered perspectives, motives and values of teamsport athletes in these broader contexts.

\section{Methods}

The driving theoretical hypothesis of this project is that homophobia has been central to the production and stratification of men's sexualities as culturally valued or subjugated. Homophobia/biphobia has been used by men as a weapon to deride other men in establishing this hierarchy (Burn, 2000; Butler, 1990; Plummer, 2001; McGuffey \& Rich, 1999). Therefore, if homophobia is on the rapid decline (Barnett \& 
Thomson, 1996; Loftus, 2001; Widmer, Treas, \& Newcomb, 1998) there might be a reconstruction of the one-time rule of homosexuality, and the relationship between sex, masculinity, and sexual identity construction. Given this potential reconstruction, it is plausible to expect individuals to give credence to multiple subject orientations and identities. As a result, greater cultural legitimacy may be given to bisexuality as a sexual identity.

In order to examine this thesis, we used participant observation and qualitative interviews of 60 (18-22 year old) players from three separate university soccer teams in the United States. In order to analyze a range of university settings, we strategically selected universities in diverse geographical locations. Politically, these locations represented strong variations in attitudinal positioning.

One team was from a small, Catholic college in the American Midwest $(n=20)$. Another represented a small liberal arts college in the American South $(n=19)$. The third was a large, liberal university located in the Northeast $(n=21)$. Of the 60 men, 52 were White, six were Black and two were Latino. In accordance with standard best practices for conducting ethnographic research, we defined our samples as each and every member of three different sports teams, and thereafter sought to collect information from those defined population samples. Therefore, the sample is valid of the team's culture, as no members are excluded. Schools, were choose to represent geographic variability, and a stratification of NCAA membership (From Division One to three).

After securing signed consent of these players and coaches (only one player refused), we (the primary and secondary authors) socialized and trained with the team for a period of ten days (during their soccer season). Attitudinal data concerning sexualities was simultaneously obtained from in-depth interviews as well as 
participant observations, as casual conversations provide a more 'real' sense of participant's views and understandings of sexualities compared to formal interviews - which often result in participants telling the interviewer what they think they want to hear (Gratton \& Jones, 2004).

Even though this was not covert research, all note-taking was conducted by recall immediately after casual conversations to reduce the visibility of researcher presence (Spradley, 1970). Thus, informants were not aware of note-taking as it occurred. This enabled players to quickly forget that we were conducting research, and we were therefore able to examine their attitudes concerning sexualities in multiple social settings.

After we felt sufficient rapport had been built between informants and us, semi-structured individual interviews took place. The order of discussion in these interviews varied; as did the exact wording of questions used. While topics were expanded upon appropriately at each site, some basic themes included whether participating in gay sex necessarily made one homosexual; whether bisexuality exists as a legitimate sexual identity; and how physical and emotional intimacy (as well as sexual desire) were understood in relation to the complexity of sexuality.

The amount of time allotted to each question varied depending upon the flow of conversation with each informant. Thus, not all questions were asked of each informant. These interviews were conducted in private; in either the office of the team's coach or in private study rooms in the university's library. All formal private interviews were audio taped and these tapes were erased after interviews were transcribed. Informants’ names have been changed in order to protect anonymity. Finally, students were given our email addresses and mobile phone numbers at the 
outset of the research, so that they could immediately contact us to request data removal, or to suggest other amendments.

Because this research seeks to analyze sexual and gendered attitudes as they may exist in concurrence or difference to hegemonic scripts, we approach this research through an inductive framework. Thus data and subsequent categories and themes emerged through a process of on-going analysis (Glaser \& Strauss, 1967). As part of this flexible analysis process, we used a thematic analysis (c.f. Braun \& Clarke, 2006) to organize, analyze and report patterns within data; as well as to provide a rich and detailed, yet complex account of our findings.

The categories 'thematized' in this research represent player-player interactions as well as player-researcher interactions within an active and naturally unfolding context. Notes were coded on the basis of their revealing an insight into the players' value or understanding of bisexuality and transcriptions were coded and cross-verified using inter-rater reliability sampling. This was the role of the third author, who co-verified our codes, and challenged our assumptions. Important, this research was not in the field, so that he was able to interrogate the first two authors without experience-bias.

\section{Decreasing Homophobia leads to decreased Biphobia}

Readers might first be surprised to learn just how inclusive the men on these team are toward sexual minorities. Contrasting the descriptions of contact sports as highly homophobic organizations (c.f. Pronger, 1990), the men on these teams demonstrated a type of masculinity that is not situated in intellectualizing or behaving in homophobic ways. Although two men expressed homophobic sentiment in private interviews, the rest were refreshingly inclusive. We found multiple stories of players 
knowing gay men or showing acceptance of and support for homosexuality; and no measurable, intellectual homophobia. "I know a load of gay guys,” Jay tells us. "My girlfriend has a ton of gay friends, so I know most of them through her. We're always hanging out as a group.” When asked whether he would maintain these friendships if he and his girlfriend broke up, Jay said, “Not all of them. But take, John, he’s become a close friend, and we'd totally hang out.” Jay, however, was not the only one to take pride in their disposition toward sexual minorities. Rod said, "I did a persuasive speech for a debate class on gay marriage. I totally believe in it. And gay adoption, too. Saying they shouldn't be allowed to is just stupid.” He added, "It shouldn’t matter who you love, and it damn well doesn't matter who you sleep with.” His teammate Danny (who was raised as a Catholic), told us, “I’m very accepting of other people, gay, straight, bi, whatever, it’s not an issue with me.”

Pro-gay discourse is expressed not only in interviews (where players have anonymity) but in social situations, too. For example, we were sitting with a group of eight soccer players in a food hall, when one of the researchers asked, “Any of you have gay or bisexual friends?” "My uncle is gay,” Brett responded. Jordan added, "My best friend from home is gay." Caden said, "I got a gay friend at home, too. He’s not my best friend but he's a good friend.” These types of conversations occurred with men in all three teams, in a variety of social locations. In other words, athletes on these three teams were not afraid to talk about their support for gay men in front of their peers. Nor were they afraid to admit to sharing homosocial intimacy with gay men.

But does the acceptance of homosexuality, necessarily indicate an acceptance of bisexuality, too? It is important to note that we almost always (but not exclusively) framed our questions and our discussions in terms of 'sexual minorities.' Or we asked, 
“Do you have any gay or bisexual friends?” But as the answers above indicate, men on these teams mostly erased bisexuals (and other sexual minorities) as specific sexual identity from these conversations. 'Gay' became the catchall for all sexual minorities.

Bisexuality was therefore somewhat, socially erased in conversations by these men. However, in-depth interviews suggest that there does nonetheless exist an extensive degree of acceptance of bisexuality among these young men. We always asked if the pro-gay attitudes these men expressed could also be applied to bisexual men. "Of course," they answered without exception. So while bisexuality is somewhat erased from casual public discussions, it is equally accepted with homosexuality. It is important to note, however, that the social acceptance of gay and bisexual men that we speak of is not examined for extension to other sexual minorities. We did not ask informants about their views on transgendered, transsexual, intersex, or asexual individuals. What is significant, is that while few of these men knew bisexual males, their social familiarity and contact with gay men lowered their homophobia, and this extended to bisexual men as well. In other words, this research suggests that decreasing homophobia also leads to decreasing biphobia.

Part of this, we assume, is due to social contact with gay men (Baunauch \& Burgess, 2010). Contact theory has been widely used in discussing decreased homophobia (McCann, Minichiello, \& Plummer, 2009). What has not been discussed, however, is that contact with gay men leads to acceptance of bi men, as well. More signicant, while some of these men report learning inclusivity through contact with a gay man, most of these men report never having been homophobic in the first place. This, too, is consistent with research that shows today's youth are not socialized into homophobia the way previous research shows they once were (Anderson, 2009). This 
decreasing homophobia seems to have led to more accepting understandings of bisexuality, too.

\section{Complex Understandings of Bisexuality}

Interviews with these 60 soccer players indicate that most of the men maintain complex understandings of the relationship between sexual orientation, sexual behaviors and gendered intimacy. For example, when these men are presented with questions designed to examine for their perspectives on the one-time rule of homosexuality, all of the men (in one way or another) dismiss this rule as overlysimplistic homophobia. For example, when we asked James, "If a straight guy had sex with a guy once, would it make him gay?” he answered, “Only if he wasn’t attracted to women.” He then looked at the interviewer as if to say, 'That's a stupid question.' The point is: however we worded our questions about the one-time rule of homosexuality, we found it was often dismissed. To these men, sex with a man can, but does not have to, equate with homosexuality.

Unlike the way men discussed sexuality in casual conversations, instead of viewing sexuality as a polarized 'either/or' identity under interview, most of these men were interested in discussing issues of sexuality through a recognition of its complexity. Mike said, “What does it really mean to be gay anyhow?” Mike found the notion of one same-sex sexual experience equating to homosexuality absurd, "Maybe my grandpa thought that way, but come on!” He added, “Having sex with a guy doesn’t necessarily make you gay. You could be gay, but you might be bi, or you might just be a straight guy having sex with a guy.”

Whether other men were capable of articulating their thoughts in the same way as Mike or not, most of these men showed an understanding that sexuality is broken 
down into at least three constituents: identity, orientation, and behavior. In understanding sexuality in this more complex perspective, they reject a binary notion of sexuality. So while they did not believe that having sex with a man automatically made one gay, they did, recognize that it might make one bisexual; although defining bisexuality proved difficult.

When asked to “describe bisexuality” many (not all) of these men initially offered an explanation that being bisexual means being sexually attracted to both men and women. As Paul stated, “It's about having equal preference for women and men.” John said, “It's when you like both the same.” But when asked to elaborate on their initial statements, most of these men were quick to clarify that it does not have to be equal attraction between men and women. “Of course,” Tim said, "You can like guys $5 \%$ of the time and girls $95 \%$ of the time, or the other way around and be bisexual. When Tim was asked if liking girls 95\% of the time, and guys 5\% if that makes one bisexual he answered, “I don’t know. You could call it that, sure. Or you could say he’s straight but he likes guys a bit. Either way, I don't really care, it doesn’t matter who you like.” And (interestingly) when Paul was asked if one can be 95\% straight and 5\% gay he said, "Of course. Most of us probably are.”

Implicit in these discussions, of course, is the acceptance that bisexuality exists. Our interviews were largely absent of the stereotypes of bisexuals as incapable of making up their mind, being in transition to coming out as gay, or being 'greedy' (although some exceptions are discussed later). Most of these men did not believe these stereotypes. When Jon was told by one researcher that "Some people think bisexuality doesn't exist, that it's just gay guys who are too afraid to say they are gay,” he responded, “That’s just stupid! I don’t know of any bisexuals at this college but 
I'm sure they exist. Nobody doubts girls can be bisexual so why doubt guys can?” He added, "Statistically, they must be out there.”

We found this an interesting theme: almost all of the men in this study maintained that bisexuality exists among men, and most (as we will get to later) even recognize bisexuality in themselves, but few know male friends who publicly identify as bisexual. Mark said, “I’ve got gay friends on campus but I don’t know of any bi guys.” He added, "I’ve met some bi girls back home. So if girls can be bi then guys can, too.” Kelvin also said that while he knows bisexual girls, he does not know any guys. "Wait a minute,” he said. "Surely I must know some.” After a moment’s reflection, and still unable to think of any, we ask why he thinks bisexual men exist, even though he doesn’t know any. "I think it is a matter of homophobia,” Kevin said: It's cool right now for girls to be into other girls. I don’t think it's bad for guys to say they are into other guys...I don't think there is much homophobia [biphobia], but it’s also not 'cool' yet. Maybe it will be in a few years. But, right now, a guy just doesn't get the same credit with his friends for doing guys as he does for doing girls. So if you're a guy, and you like girls [too,] I guess it just make sense to say you're straight.

Tim maintained that bisexuality is as common for men as it is for women, "If, whatever, 2 out of 5 girls are into other girls, well you know it's gonna be that way for guys, too.” Clint, who grew up on a farm in the Midwest, agreed, saying that he believes that the difference between gay and straight is "blurry.” He added, "I have gone to gay bars, I've even kissed one of my friends. Does that make me gay? Does it make me bisexual?” He continued, “This categorizing people stuff is kind of stupid, don’t you think?” We expressed to Clint that while we understand that it may very well be stupid, it is nonetheless a social phenomenon; and we wonder why he chooses 
to describe himself as straight. Clint smiled, "You got me there. I guess it’s because I’ve only been with girls, so far.”

Others also intellectually challenged the polarization of sexual binaries, even if they do not identify as bisexual. Tom said, “I don’t get it. Why do we have to be straight or gay, or whatever? Why can’t we just be?” Tom’s teammate Danny said, “Or why can’t we be somewhere between. Can you really be a hundred percent something?” Still, both of these men also identify as heterosexual.

Accordingly, interview data suggests that while these men are not identifying as bisexual, they (at least) intellectualize bisexuality. They demonstrate that, at an intellectual level, sexuality is positioned on a continuum. In this respect, the intellectual understanding of sexual perspectives for these men might best be understood from a queer perspective, as they discuss the deconstruction of sexual identities and categorization (Sedgwick, 1990; Seidman, 1996; Jagose, 1996). What is perhaps even more interesting, however, is that not only do they recognize that bisexuality exists, but at an intellectual level, they recognize their own bisexuality, too.

\section{Recognizing Bisexuality in Themselves}

Most of the men in this research comment that they understand bisexuality to encompass a broad spectrum of variables, while a minority predominantly categorize bisexuality as the presence of physical attraction, and/or acting upon this attraction. For example, (representing the minority view) Justin said, “Thinking or saying a guy is good looking doesn’t show bisexuality, and loving straight male friends isn’t bisexual either.” Justin therefore positions sexuality as being defined by sexual desire/behavior alone. However, most men complicate this perspective. 
Indeed, the majority of these men recognized emotional attachment and emotional expression as components of sexuality, too. And perhaps this is why nearly all of the men we interview recognized some bisexuality in themselves. "I think we're all bisexual to some degree,” Sean said. “I mean, I don’t think it’s purely a physical thing, I think it’s an emotional thing, too.” When asked to expand upon this idea of bisexuality being a universal sexuality, he said, “All I’m saying is it’s more complicated than just the physical.” Sean's reasoning rejects any definition of sexuality based on sexual behavior alone: and this is the shared perspective.

Corey maintains that bisexuality is human nature at its best. "Bisexuality is fascinating,” he said. “Someone who can dig [be attracted to] both men and women is fascinating because they don’t distinguish - they just dig humans. And there’s something cool about that. It's beautiful.” Corey also touched upon an area that most of the men in this study identify with — they are not afraid to express their love for their male friends. "I love Dom,” Corey says. "I mean I really love him. Call it a bromance if you want, but he’s my boy...There's nothing I can’t talk with him about.” Whereas boys and men have traditionally avoided homosocial intimacy (Pollack, 1998), or at least the verbal recognition of that intimacy, these men are fluid and proud of their verbal expressions of love for their mates. This was true regardless of the team studied: these men expressed a great deal of affection. Jay said, "I love John, he’s my friend, my bro. I'd do anything for him.” And when asked how his love for his best friend compared to the love he has for his girlfriend (of 4 years) he answered, “It’s close. You ever watch Scrubs [the TV show]?” he asks. “It's like me and John are like JD and Turk [two of the main male characters who are emotional but not physical lovers].” This type of affection was commonplace among teammates: they were not shy about calling their affection love. Clint, Sean, Jay, and multiple 
others postulate that there is a connection between love and sexuality. One of the players said, “I love my best friend more than my girlfriend, doesn't that make me a little gay?”

Thus, not only do we find an overt acceptance of homosexuality and bisexuality among a group of men traditionally understood to be characterized by homophobia; and not only do we find that these men reject the one-time-rule of homosexuality and complicate bisexuality; but we also find that (at some level) these men recognize bisexuality in their own personal (not public) identities. In one-on-one interviews, 48 out of 60 identify some bisexuality in their own lives.

When given verbal scale of zero to ten, with zero being $100 \%$ heterosexual and ten being $100 \%$ homosexual $^{1}$, twelve of the men score themselves as a zero, 32 scored themselves as a one, twelve scored themselves as a two, and four scored themselves as a three.

We asked those whom did not score themselves as a zero why not. "I'd probably say I’m a two,” Alex told us, “And why not a zero?” we asked. “Because I like to hug guys,” Alex responded. “It's not like it is sexually pleasurable contact, but I’m really comfortable with male contact.” Caden also rated himself as a two. “Behavior wise, I'd say a two or three, I’m down with physical contact. And I’ve thought about what it would be like to be gay. Not that I question my sexuality. Everyone probably has thought about it at some point, even if they don't talk about it.” Caden also gives us his interpretation of where others might place him on the scale. "I think outsiders would put me as a five or something like that, because other people might label some of my behaviors as gay, or not what someone who was completely

\footnotetext{
${ }^{1}$ We did not use the Kinsey scale or Klein Sexual Orientation Grid to draw our responses. Instead, we adapted these into a zero-to-ten scale, thinking this might elicit a broader range of scores and thus prevent these men from defensively scoring themselves as zero.
} 
straight should do.” He laughed, “Sometimes I just go along with it to keep people guessing. Like, I’ll hug people and hold on for a bit longer than they expect.”

Luke told a similar story of keeping his sexuality ambiguous:

I was holding this friend of mine. We were both topless in my room at a party and this girl walked in. We thought we'd be smart and say we were gay to see what her reaction would be and if she would believe it or freak out or whatever. She was totally cool with it and ended up telling us she was bisexual and telling us all about it [he laughs]. I guess she trumped our story!”

Two other men also told us that they had thought about what it would be like to be gay, and had also discussed their own sexuality with friends. Both concluded that they were straight and now rate themselves on the scale as a two. Others, rated themselves a one or two because they have had some form of sexual contact with a man. "Well, I’ve kissed guys before: a couple of times, on the lips, and a million times on the cheek. Conventionally that probably doesn't make me 100\% straight,” John said.

Correspondingly, we asked those who scored themselves as a zero why they did so. Here, almost all of these men explained their straightness in relation to an absence of gay/bi behavior. "I’ve never done anything remotely sexual with a guy," Mike said. Jessie said, “I’m strictly attracted to women, and I'd never have intercourse with a guy.” Adam also rated himself as a zero but he was clear to identify that this rating is not borne out of homophobia.

Thus, firstly we found that the majority of these men give cultural currency to bisexuality as a legitimate sexual identity. Second, they maintained inclusive attitudes toward homosexuality and bisexuality. Third, although none identified as bisexual publicly, most of these men intellectually understand some bisexuality in their lives. 
One can argue as to what definitions of bisexuality are, whether these men should include themselves as being bisexual based on emotional intimacy, or whether or not these men might simply have been saying that they were bisexual because they perhaps thought that this is what the researchers desired to hear. However, it is a significant finding that these men do not defensively assert their pure heterosexuality. This is consistent with Anderson’s (2009) recent work on masculinities, where he describes not only a softening of masculinity, but a blurring of gender and sexuality boundaries; it adds to empirical evidence that suggests many heterosexuallyidentifying undergraduate men are increasingly moving away from aggressively defending their sexuality as " $100 \%$ straight."

\section{Old Myths Die Hard}

While the vast majority of these men offer a refreshing emotional and intellectual outlook on men who have sex with men, in the interests of representing the data accurately, it is also important to note that a handful maintained dispositions about bisexuality that resemble what older research has found. For example, Klein (1993) suggested that bisexual men are oftentimes understood to be either non-existent, neurotic or hypersexual. We found some evidence of this sentiment in some of these men, too.

Steve jokingly encapsulated some of this sentiment by suggesting that, “Maybe they [bisexuals] are just horny.” David positioned bisexuals as curious or experimenting, saying, “They are gay and like having sex with women also, or they're straight and they are curious.” But while David described bisexuality as having two forms (you're either predominantly gay or straight), he asserted that he would call them bisexual if that's how they identified. 
Two men positioned bisexuals as neurotic: a psychological state of confusion with one’s sexuality. Mike, for example, said, "I think it means to be unsure of yourself as to who you are. Unsure of what you want.” Rod told us that he thinks bisexuality might be, “a little bit of confusion.” “Most bisexual people don’t know what they are, I think," he said. "You probably fall for one or the other in the end. It might just take you a while to decide.” Brett said that bisexuality is what people call themselves when they are in transition between straight and gay. "I'd call them very undecided. I've always thought of bisexuality as a transition period-they haven't figured it out yet [whether they are straight or gay].”

However, most of these men are not entrenched in their positions. When they are questioned about them, they do not feel strong desire to be correct about their positions. Thus, after hearing of our perspective on matters, most would agree that there was merit to our argument that matters are more complex. This indicates that although there are still some myths about bisexuality circulating in youth culture, those myths do not appear to be generated by biphobia.

\section{Discussion}

By interviewing and observing three geographically distinct groups of heterosexual male teamsport athletes (a traditionally homophobic social group, c.f. Messner, 1992; Pronger, 1990), this research investigated young soccer-playing men’s understandings of bisexuality. We explored the attitudes these heterosexually self-identified men maintained toward sexual identity categorization, and how they contextualized their own sexual identities. We found that, although a few students still deny bisexuality as a legitimate category of sexual desire/identification, the vast majority recognize bisexuality as a legitimate sexuality for men. Many even challenge the binaries of 
homosexuality and heterosexuality, suggesting that sexuality is best understood as a spectrum.

We suggest that the acceptance of bisexuality we find among these 60 men is related to their social acceptance of gay men. This, in itself is a noteworthy finding, because teamsports are traditionally described as bastions of homophobia (WolfWendel, Tomas \& Morphew, 2001). As surprising as these inclusive attitudes may seem (to some), we highlight that they are consistent with other research that shows that homophobia is decreasing rapidly for men of this age group (18-22). For example in the mid 1990’s (Herek \& Capitanio, 1995) found 64\% of men agreed with the statement 'I think male homosexuals are disgusting' but on research of university students in 2002 (but published in 2010) Baunach and Burgess show that this number fell to just 24\%; and this is in the deep American south.

The decreasing stigma about sex with men is likely a product of multiple cultural influences: the media, decreasing religious fervor, and the Internet. And, as Anderson (2008) has previously shown, when men exist within a culture of decreased homophobia more space is created for the open discussion and complex understanding of sexual behaviors and identities that were once erased or stigmatized in a homophobic culture.

While cultural homophobia is decreasing because of larger, macro-level, changes to North American society, it is also important to note that homophobia is also decreasing because of increased social contact with gay men (Baunach \& Burgess, 2010). It is interesting to note, however, that the inclusivity toward bisexuality we discuss here is not attributable to increased social contact with bisexual men. As a collective, these participants knew very few bisexual men. Instead it is explained by a latent effect of increased contact with gay men and improving attitudes 
toward homosexuality. A latent affect of the reduction of homophobia seems to be the transference of this acceptance to bisexuality.

While all but two of our informants intellectualize no homophobia or biphobia, many remain personally fearful that their peers are not as accepting and tolerant of gay and bisexual men as they are. This was particularly the case in the southern school. Conversely, it was not-at-all the case in the large, liberal university from the northeast. However, even here, where the explicit and implicit norms of the team are to be inclusive of men who have sexual desire for men (as they were in the north); and here, where most of the men intellectualize some bisexuality in their own identities, they still do not publicly identify as bisexual. We found this interesting. While only 12 of the 60 men identified as 100\% straight (in one-on-one interviews), none publicly identified as bisexual—including those (few) who had experienced some form of same-sex sexual contact with another man.

These findings therefore raise the question of why these men do not identify as bisexual. Even after team discussions have made it very clear that none of the players on the Northeast team harbored intolerance, and even after players discussed with one another that they identified as a one or two on our scale, none publicly identified as bisexual. What is clear is that these men took into account multiple variables in understanding sexuality, emotional preference, social preference, and selfidentification, but they still privilege sexual attraction in choosing how to self-identify. In this sense, we identify a complex appropriation of gay/bi behaviors by selfidentified straight men. This is consistent with the complex way Klein (1993) understands bisexuality.

There are a few ways of analyzing this. First, it may very well be that even in light of their tolerance and acceptance of bisexuality and homosexuality, the fact that 
these men are increasingly engaging in same-sex intimacies, yet still identifying as straight, demonstrates the continued stigma attached to minority sexual identity categories (not necessarily the sex act). Another reason may be the term bisexual itself. It was very common for men in this study to say, "I’m a little bit gay," and to then describe the love they maintain for a friend, an increased fashion sense, or other sensibility that is culturally coded as gay. These men are clearly comfortable recognizing that sexuality is more complex than just sex, and they are willing to recognize some 'gay' in themselves. But it may be that they fail to identify as bisexual because, whereas 'gay' and 'straight' have a sexual implication but also a sensibility that incorporates non-sexual behaviors, there is not a similar "sex and sensibility" word for bisexual. In other words 'gay' is to homosexual as 'straight' is to heterosexual: and both are softer, broader, less clinical terms. But what is the softer, broader, less clinical and-yes_-less sexual term associated with bisexuality?

The term metrosexual partially fills this void, and a number of the men we spoke to identify this way. But metrosexual is too heavily laden with just one behavior, dressing well. Others described having a 'bromance' but this too also describes just one characteristic (emotional connection). So, at least for now, decreasing homophobia and the loosening of heteromasculine boundaries means that while men are more willing to intellectually recognize bisexuality as a legitimate sexual identity — and even to recognize bisexuality in their own, personal identities— straight men are not claiming a bisexual 'middle ground.' Perhaps some of this would be rectified with the popular construction of a word that captures the multiple characteristics that Klein (1993) identifies; perhaps a word without 'sexual' at it's core. 
Finally, we do not attempt to generalize these findings to all young men in America. Although the men in our study hail from geographically diverse locations, they also represent an educated cohort of youth. Previous research links higher education to more positive attitudes toward homosexuality (Herek \& Capitanio, 1995; Lewis, 2003). It is also possible that undergraduate men maintain more opportunity to have social contact with gay men, compared to those who do not attend college (Herek, 1994). Still, we highlight that the majority of these men talk about how they came to college already accepting of homosexuality; thus, college attendance does not completely explain the results we find with these young men. 


\section{References}

Anderson, E. (2002). Openly gay athletes: Contesting hegemonic masculinity in a homophobic environment. Gender \& Society, 16(6), 860-877.

Anderson, E. (2005). In the game: Gay athletes and the cult of masculinity. State University of New York Press.

Anderson, E. (2005). Orthodox \& inclusive masculinity: Competing masculinities among heterosexual men in a feminized terrain. Sociological Perspectives, 48(3): 337-355.

Anderson, E. (2008a). Inclusive masculinities in a fraternal setting. Men and Masculinities, 10(5), 604-620.

Anderson, E. (2008b). "Being masculine is not about who you sleep with...”: Heterosexual athletes contesting masculinity and the one-time rule of homosexuality. Sex Roles, 58, 104-115.

Anderson, E. (2008c). "I used to think women were weak": Orthodox masculinity, gender segregation, and sport. Sociological Forum, 23(2), 257-280.

Anderson, E. (2009). Inclusive masculinity: The changing nature of masculinities. New York: Routledge.

Barnett, S., \& Thomson, K. (1996). Portraying sex: The limits of tolerance. In R. Jowell, J. Curtice, A. Park, L. Brook, \& K. Thomson (eds.), British Social Attitudes, the $13^{\text {th }}$ Report. Aldershot, Hants: Social and Community Planning Research.

Barrios, B. A., Corbitt, L. C., Estes J. P., \& Topping, J. S. (1976). Effect of a social stigma on interpersonal distance. Psychological Record, 26(3), 343-348.

Baunauch, D. \& Burgess, E. (2010). Southern (dis)comfort: Sexual prejudice and contact with gay men and lesbians in the south. Sociological Spectrum, 30, 30-64.

Bérubé, A. (1991). Coming out under fire: The history of gay men and women in worldwar II. New York: Plume.

Bogle, K. A. (2008). Hooking up: Sex, dating, and relationships on campus. New York: New York University Press.

Braun, V., \& Clarke, V. (2006). Using thematic analysis in psychology. Qualitative Research in Psychology, 3, 77-101.

Britton, D. M., \& Williams, C. L. (1995). Don’t ask, don’t tell, don’t pursue: Military policy and the construction of heterosexual masculinity. Journal of homosexuality, 30(1), 1-21. 
Burn, S. M. (2000). Heterosexuals' use of "fag” and "queer" to deride one another: a contributor to heterosexism and stigman. Journal of Homosexuality, 40(2), 1-11.

Burstyn, V. (1999). The rites of men: manhood politics and the culture of sport. Toronto: University of Toronto Press.

Burton-Nelson, M. (1994). The stronger women get, the more men love football: Sexism and the American culture of sports. New York: Harcourt Brace.

Butler, J. (1990). Gender Trouble: Feminism and the Subversion of Identity. New York: Routledge.

Davis, J. (1991). Who is black? One nation's definition. University Park, PA: Pennsylvania State University Press.

Denizet-Lewis, B. (2003, August 3). Double lives on the down low. New York Times Magazine, p.28.

Eigenberg, H. M. (2000). Correctional officers and their perceptions of homosexuality, rape, and prostitution in male prisoners. The Prison Journal, 80(4), 415-433.

Gear, S. \& Ngubeni, K. (2002). Daai ding: Sex, sexual violence and coercion in men's prisons Johannesburg: Centre for the Study of Violence and Reconciliation.

Glaser, B. G. \& Strauss, A. L. (1967). The discovery of grounded theory: Strategies for qualitative research. New York: Aldine de Gruyter.

Gratton, C. \& Jones, I. (2004). Research methods for sport studies. Routledge: London.

Harris, M. (1964). Patterns of Race in the Americas. Westport, CT: Greenwood Press.

Harris, J., \& Clayton, B. (2007). The first metrosexual rugby star: Rugby union, masculinity, and celebrity in contemporary Wales. Sociology of Sport Journal, 24, 145-164.

Herek, G. M. (1994). Assessing heterosexuals' attitudes toward lesbian and gay men: A review of empirical research with the ATLG scale. In B. Greene \& G. M. Herek (eds.), Lesbian and gay psychology: Theory, research, and clinical applications (pp. 206-228). Thousand Oaks, CA: Sage.

Herek, G. M. (2002). Psychological heterosexism and anti-gay violence: The social psychology of bigotry and bashing. In M. Kimmel \& M. A. Messner (eds.), Men’s lives (pp. 254-256). Boston, MA: Allyn \& Bacon.

Herek, G. M. \& Capitanio, J. P. (1995). "Black heterosexuals attitudes toward lesbian and gay me in the united states. Journal of Sex Research, 32, 95-105.

Ibson, J. (2002). Picturing men: A century of male relationships in everyday American photography. Washington, DC: Smithsonian Institution Press. 
Jackson, S., \& Scott, S. (2003). Whatever happened to feminist critiques of monogamy? In H. Graham, A. Kaloski, A. Neilson, \& E. Robertson, (eds.) The feminist seventies. York: Raw Nerve Books.

Jagose, A. (1996). Queer theory: An introduction. New York: New York University Press.

Johnson, A. C., Mercer, B., Erens, A., Copas, S., McManus, K. \& Wellings, K. (2001). Sexual behaviour in Britain: Partnerships, practices, and HIV risk behaviours. The Lancet, 358(9296): 1835-1842.

Joyner, K. \& Laumann, E. (2001). Teenage sex and the sexual revolution. In E.O. Laumann \& R.T. Michael (eds.), Sex, love, and health in America: Private choices and public consequences. Chicago: University of Chicago Press.

Kaplan, D. (2006). Public Intimacy: Dynamics of seduction in male homosocial interactions. Symbolic Interaction, 28(4), 571-595.

King, J. L. (2004). On the down low: A journey into the lives of "straight" Black men who sleep with men. New York: Broadway Books.

Klein, A. M. (1993). Little big men: Bodybuilding subculture and gender construction. Albany, NY: SUNY Press.

Klein, F. (1993). The bisexual option ( $2^{\text {nd }}$ ed.). Binghamton, NY: The Haworth Press.

Latinen, A., \& Tiihonen, A. (1990). Narratives of men's experiences in sports. International Review for the Sociology of Sport, 25, 185-202.

Laumann, E. O., Gagnon, J. H., Michael, R. T. \& Michaels, S. (1994). The Social organisation of sexuality: Sexual practices in the United States. Chicago: The University of Chicago Press.

Loftus, J. (2001). America's liberalization in attitudes toward homosexuality, 1973 to 1998. American Sociological Review, 66(5), 762-82.

McCann, P.D., Minichiello, V., \& Plummer, D. (2009). Is homophobia inevitable? Evidence that explores the constructed nature of homophobia, and the techniques through which men unlearn it. Journal of Sociology, 45(2), 201-220.

McGuffey, C. S. \& Rich, B. L. (1999). Playing in the gender transgression zone: Race, class, and hegemonic masculinity in middle childhood. Gender \& Society, 13(5), 608-627.

Messner, M. A. (1992). Power at play: sports and the problem of masculinity. Boston, MA: Beacon Press.

Messner, M. A. (2004). Becoming 100 percent straight. In M. Kimmel \& M. Messner (eds.), Men's Lives $6^{\text {th }}$ ed (pp. 421-426). Boston: Allyn \& Bacon. 
Mills, M. (1997). Football, desire, and the social organization of masculinity. Social Alternatives, 16, 10-13.

Mohr, J. J., Israel, T., \& Sedlacek, W. E. (2001). Councelors' attitudes regarding bisexuality as predictors of counselors' clinical responses: An analogue study of a female bisexual client. Journal of Counselling Psychology, 48(2), 212-222.

Ochs, R. (1996). Biphobia: It goes more than two ways. In B. A. Firestein (ed.), Bisexuality: The psychology and politics of an invisible minority (pp. 217-239). Thousand Oaks, CA: Sage.

O’Donnell, K. A., Walters, A. S., \& Wardlow, D. L. (1998). Gender and team sports: The arena where agency meets communion. In E. Fischer \& D. L. Wardlow (eds.), Proceedings of the association for consumer research (pp.159-177).

Pascoe, C. J. (2003). Multiple masculinities? Teenage boys talk about jocks and gender. American Behavioural Scientist, 46(10), 1423-1428.

Plummer, D. (1999) One of the boys: Masculinity, homophobia and modern manhood. New York, NY: Haworth Press.

Price, M. \& Parker, A. (2003). Sport, sexuality and the gender order: Amateur rugby union, gay men, and social exclusion. Sociology of Sport Journal, 20(2), 108-126.

Pringle, R., \& Markula, P. (2005). No pain is sane after all: A Foucauldian analysis of masculinities and men's experiences in rugby. Sociology of Sport Journal, 22(4), 472-497.

Pronger, B. (1990). The arena of masculinity: Sports, homosexuality, and the meaning of sex. New York, NY: St. Martin’s Press.

Reis, A. (1961). The social integration of peers and queers. Social Problems 9(2): 102-120.

Ricciardelli, L. A., McCabe, M. P., \& Ridge, D. (2006). The construction of the adolescent male body through sport. Journal of Health Psychology, 11, 577-587.

Schrack-Walters, A., O’Donnell, K. A., \& Wardlow, D. L. (2009). Deconstructing the myth of the monolithic male athlete: A qualitative study of men's participation in athletics. Sex Roles, 60, 81-99.

Schwartz, P. (1995). The Science of Sexuality still needs Social Science. The Scientist 9(3): 12.

Sedgwick, E. K. (1990). Epistemology of the Closet. Berkeley, CA: University of California Press.

Seidman, S. (1996). Queer theory sociology. Oxford: Blackwell. 
Southall, R., Nagel, M., Anderson, E., \& Polite, F., \& Southall, S. (2009). An investigation of the relationship between college athletes' gender and sexual orientation attitudes. Journal of Issues in Intercollegiate Athletics, 2, 62-77.

Spradley, J. P. (1970). You owe yourself a drunk: An ethnography of urban nomads. Boston, MA: Little \& Brown.

Stepp. L.S. (2007). Unhooked: How young men pursue sex, delay love, and lose at both. NewYork, NY: Riverhead Books.

Tanenbaum, L. (1999). Slut: Growing up with a bad reputation. New York: Seven Stories Press.

Thompson, E. M. (2006). Girl friend or girlfriend? Journal of Bisexuality, 6(3), 47-67.

Widmer, E. D., Treas, J., \& Newcomb, R. (1998). Attitudes towards nonmarital sex in 24 countries. Journal of Sex Research, 35(4), 349.

Wolf, N. (1997). Promiscuities. London: Chatto and Windus.

Wolf-Wendel, L. E., Toma, J. D., \& Morphew, C. C. (2001). How much difference is too much difference? Perceptions of gay men and lesbians in intercollegiate athletics. Journal of College Student Development, 42(5), 465-479. 